\title{
A comparative study of three non-invasive systems for measurement of hemoglobin with hemocue system having coulter LH750 as reference value
}

\begin{abstract}
Context: The measurement of hemoglobin $(\mathrm{Hb})$ is a priority in blood donor's selection. In recent years non-invasive methods have appeared based on spectrophotometry and spectroscopy for $\mathrm{Hb}$ measurement, avoiding the inconvenience of the fingerstick systems used in the developed countries.

Objective: To analyze three non-invasive methods: NBM200 (2L0177 probe) which uses spectroscopy occlusion, Haemospect (01.81.191 version) with spectroscopic measurement and quantitative evaluation and Pronto7 TM (2.3.16 version) which uses spectrophotometry with multiple wavelengths, and to compare these methods with the HemoCue 301 (invasive fingerstick system) and a venous $\mathrm{Hb}$ predonation sample analyzed in a hematology analyzer (Coulter LH 750) as a reference value.

Design: A prospective study was performed in 2014 with 159 blood donors (102 men and 57 women). Operators who used four methods filled out a questionaire about the usability. The results were entered into a database and a statistical analysis was performed, estimating correlation index and Blatman Almant plot. We analyzed rejected falsely and accepted falsely results with the Coulter as the reference standard.

Results: With HemoCue $95.6 \%$ of donors were properly accepted, $91.82 \%$ with Haemospect and NBM200 and $89.94 \%$ with Pronto7. Blood donors improperly accepted reached the $0.63 \%$ with HemoCue, $1.26 \%$ with Haemospect and NBM2000 and $2.52 \%$ with Pronto 7 , and $3.7 \%$ were wrongly excluded with HemoCue, $5.66 \%$ with NBM200, 6,62\% with Haemospect and 8,81\% with Pronto7. Correlation index was better between HemoCue and Coulter (0.859) than the other systems (Haemospect 0.416; Pronto7 0.618; NBM200 0.648).

Conclusion: The value of hemoglobin with HemoCue shows the best correlation with the LH750, being lower for the rest, although acceptable, especially with P7 and NBM200. But the three devices could be used as screening test for blood. Any device is superior to any other and we should analyze its cutoff to avoid the high percentage of falsely rejected. As for handling, the 4 systems meet expectations
\end{abstract}

Volume I Issue 3 - 2015

\author{
Ángel Luis Pajares Herraiz, Juan Diego \\ Rodriguez Gambarte, Blanca Eguía Lopez, \\ Cristina Teresa Fernandez Maqueda, Carmen \\ Coello de Portugal, Maria del Valle Flores \\ Sanz \\ Centro Regional de Transfusión Toledo-Guadalajara \& Servicio \\ de Transfusión Complejo Hospitalario de Toledo
}

\begin{abstract}
Correspondence: Ángel Luis Pajares Herraiz, Director Centro Regional de Transfusión Toledo-Guadalajara \& Servicio de Transfusión Complejo Hospitalario de Toledo,Avenida Barber 30,TOLEDO, España, Tel, 34925269200 (4918I), Fax 34925228164,Email alpajares@sescam.jccm.es
\end{abstract}

Received: July 21, 2015 | Published: September 18,2015

Keywords: haemoglobin, blood donors, hemocue, NBM200, pronto7, haemospect, CBC, coulter LH 750

Abbreviations: $\mathrm{Hb}$, hemoglobin; $\mathrm{CBC}$, cell blood counter; $\mathrm{MCV}$, mean corpuscular volume; $\mathrm{MCH}$, mean corpuscular hemoglobin, RDW, red distribution wide; BP, blood pressure

\section{Introduction}

Blood and blood components are essential for treatment, support of patients and surgeries. These products come from the solidarity of our non-remunerated blood donors who must meet selection criteria in order to avoid risks to themselves and to the receptors. Selection criteria are based on scientific evidence reflected in different national and European regulation. ${ }^{1,2}$ On the other hand to achieve greater transfusion safety for our patients needs a greater frequency of donations from the blood donors so there are a consequent risk of anemia and one of the requirements for blood donation is the measurement of Hemoglobin or/and Hematocrit in the donor, in order to avoid such risk and protect their health. ${ }^{3}$ Hemoglobin values are limited for blood donation in different geographical areas.
For instance, 12.5 and $13 \mathrm{~g} / \mathrm{dl}$ for men and women respectively in Brazil, ${ }^{4} 12.5 \mathrm{~g} / \mathrm{dl}$ in the $\mathrm{USA}^{5,6}$ and $13.5 \mathrm{~g} / \mathrm{dl}$ for men and $12.5 \mathrm{~g} /$ $\mathrm{dl}$ for woman in Europe (including Spain), as published by Europe's Council, ${ }^{1}$ which also determines donors can donate blood 4 and 3 times in 1 year respectively. ${ }^{1,2}$ Failure to provide such value at the moment of the donation represents the largest percentage of exclusion in blood donors in different countries, being higher in females than in male. ${ }^{7-10}$ In our center, where the excluding donors index is $6.87 \%$ throughout the area we cover, $\mathrm{Hb}$ exclusion accounts for $45.70 \%$ of all the exclusions $(3.13 \%$ of donors are excluded for this reason), being this the deferral cause in $32.62 \%$ of men and $53.70 \%$ of women respectively.

There have been and there are different methods for anemia screening more or less invasive, but nowadays fingerstick methods are widespread used in developed countries. These systems range from the density copper sulfate method, that is very subjective and does not give quantitative results, ${ }^{11}$ or the microhematocrit method that is too 
much time consuming and it is not as $\mathrm{safe}^{12}$ as the spectrophotometric determination by HemoCue for example. Although this system does not reflect the state of iron storage in the individual, it is an easy, quick and validated method for $\mathrm{Hb}$ measure. ${ }^{7,13-17}$

In the last few years, many non-invasive methods for $\mathrm{Hb}$ measure, which have been used previously in surgical areas (perioperative and intraoperatively) as well as in intensive care units, have been developed in order to avoid digital puncture and the usual discomfort to donors and to improve their loyalty in blood donation. ${ }^{18-21}$ Various studies have compared these systems with other hemoglobin detection methods in blood donors with apparent promising results as a routine screening method. ${ }^{22,23}$ These new methods are based on the occlusion spectroscope principle (NBM 200), spectrophotometry with multiple wavelengths of light in the sensor (Pronto-7) ${ }^{19,21}$ or spectroscopic measurement by quantitative evaluation (Haemospect). ${ }^{24,25}$

The objective of our study was to analyze the feasibility using these news devices compared with our routine screening method, which is an invasive method to measure capillary $\mathrm{Hb}$ (HemoCue 301), validated long time ago, and to compare with the venous $\mathrm{Hb}$ analyzed in an automatic analyzer (Coulter LH 750) used as reference method or gold standard.

\section{Material and methods}

A prospective study was performed with 159 blood donors (102 men and 57 women) who attended our Blood Transfusion Center, located in the Hospital Virgen de la Salud of Toledo, in the period between July $31^{\text {st }}$ and September $12^{\text {th }}$ of 2013. The blood donor was informed on a national regulation basis, and he consented the procedure. All blood donors underwent an interview and medical examination according to our protocols, including heart rate, blood pressure and $\mathrm{Hb}$ measure with $\mathrm{HemoCue}$. In addition, we measured $\mathrm{Hb}$ with the three non-invasive devices according to the supplier's instructions and before the collection of whole blood unit we performed an extraction of venous blood sample to study with CBC, which was performed to all donors currently at blood donation time together with other mandatory testing for serologic and immunologic studies. The measure of the $\mathrm{Hb}$ with the different systems was done at room temperature, between $21^{\circ} \mathrm{C}$ to $25^{\circ} \mathrm{C}$.

Data concerning gender, age, number of total blood donations, number of donations in the last year, hemoglobin, hematocrit, MCV, $\mathrm{MCH}, \mathrm{RDW}$, heart rate and Blood Pressure (systolic, diastolic and BP

Table I Summary of technical characteristics of the different devices mean) were recorded. A questionnaire was done by the operators who used non-invasive methods in order to evaluate the usability, speed of the method or time to readiness, cleaning and maintenance, intrinsic errors, sensitivity to ambient light and handling, this survey was made with a scale and evaluated from 0 (unsatisfactory) to 5 (excellent).

\section{Fingerstick samples and $\mathrm{Hb}$ screening}

Samples from each donor were obtained by fingerstick to test the $\mathrm{Hb}$ with HemoCue $\mathrm{Hb} 301 \mathrm{Hb}$ (HemoCue AB, Angelholm, Sweden) according to the supplier instructions. The system consists of an analyzer with micro-buckets made of polystyrene plastic used as a pipette and a measuring cuvette. A volume of $10 \mu \mathrm{L}$ of the blood sample is inserted into the cavity by capillary action. The measurement is made spectrophotometrically in the analyzer, which measures the absorption of blood in an isosbestic point on $\mathrm{Hb} / \mathrm{HbO}_{2}$. The analyzer performs the measurement using two wavelengths to compensate the turbidity. The HemoCue $\mathrm{Hb} 301$ system is calibrated against the hemoglobincianuro method, the international reference method for determining the concentration of hemoglobin in blood. No additional calibration is needed because it is calibrated at the factory. The test is done between 45 to 60 seconds. This is the routinely used method in our Blood Transfusion Center and other points of care to donors for $\mathrm{Hb}$ pre-donation screening.

\section{Invasive method for venous $\mathrm{Hb}$ blood control}

Previous to blood donations, venous samples from all donors were obtained with tubes extracted currently for different blood analysis in our center. Tubes were used with EDTA (Ethylene-diamine tetraacetic Acid) as anticoagulant and blood count was performed within 12 hours post-extraction in an automatic hematology analyzer (COULTER ${ }^{\circledR}$ LH 750 System, Beckman Coulter, Brea CA, USA) after analyzing different variables in the counter using commercially available controls. The values reported by the analyzer were considered as gold standard and benchmark for blood controls by HemoCue and other methods used

\section{Hemoglobin screening by non-invasive systems}

In our study we used three non-invasive methods to screen $\mathrm{Hb}$, the NBM200 system (2L0177 Probe; Orsense Ltd, New Ziona, Israel), the Haemospect ${ }^{\circledR}$ (01.81.191 version; MRB Optical Systems GmbH \& Co. KG, Wuppertal, Germany) and Pronto7 TM (2.3.16 version, Masimo Corporation, Irvine, USA). A summary of technical characteristics of these different devices are shown at Table 1.

\begin{tabular}{|c|c|c|c|c|c|c|c|c|c|}
\hline & $\begin{array}{l}\text { Weight } \\
\text { (g) }\end{array}$ & $\begin{array}{l}\text { Dimensions } \\
(\mathrm{mm}) \text { wide } \\
x \text { deep } x \\
\text { height }\end{array}$ & $\begin{array}{l}\text { Self-test(S) } \\
\text { calibration } \\
\text { (C) }\end{array}$ & $\begin{array}{l}\text { Range } \\
\text { Hb } \\
\text { g/dl }\end{array}$ & $\begin{array}{l}\text { Operating } \\
\text { temperature } \\
\left({ }^{\circ} \mathrm{C}\right)\end{array}$ & Invasive? & Principle & Measurements & $\begin{array}{l}\text { Test time } \\
\text { (seconds) }\end{array}$ \\
\hline $\begin{array}{l}\mathrm{Hb}- \\
\mathrm{Hc}\end{array}$ & 500 & $|60 \times| 40 \times 70$ & No & $0-25.6$ & Oct-40 & Yes & $\begin{array}{l}\text { Absorbance of whole } \\
\text { blood at an } \mathrm{Hb} / \mathrm{HbO}_{2} \\
\text { isosbestic point; } \\
\text { double wavelength } \\
\text { measuring method, } \\
506 \text { and } 860 \mathrm{~nm}\end{array}$ & $\mathrm{Hb}$ & $15-45$ \\
\hline $\begin{array}{l}\mathrm{Hb}- \\
\text { NBM }\end{array}$ & 900 & $224 \times 182 \times 75$ & $S$ & I8-Jun & $0-40$ & No & $\begin{array}{l}\text { Occlusion } \\
\text { spectroscopy, 600- } \\
\text { I500nm }\end{array}$ & $\begin{array}{l}\mathrm{Hb} \\
\mathrm{PR}\end{array}$ & $90-120$ \\
\hline
\end{tabular}


Table Continued....

\begin{tabular}{|c|c|c|c|c|c|c|c|c|c|}
\hline & $\begin{array}{l}\text { Weight } \\
\text { (g) }\end{array}$ & $\begin{array}{l}\text { Dimensions } \\
(\mathrm{mm}) \text { wide } \\
x \text { deep } x \\
\text { height }\end{array}$ & $\begin{array}{l}\text { Self-test(S) } \\
\text { calibration } \\
\text { (C) }\end{array}$ & $\begin{array}{l}\text { Range } \\
\text { Hb } \\
\text { g/dl }\end{array}$ & $\begin{array}{l}\text { Operating } \\
\text { temperature } \\
\left({ }^{\circ} \mathrm{C}\right)\end{array}$ & Invasive? & Principle & Measurements & $\begin{array}{l}\text { Test time } \\
\text { (seconds) }\end{array}$ \\
\hline $\begin{array}{l}\text { Hb- } \\
\text { Ham }\end{array}$ & 544 & $115 \times 210 \times 42$ & C & -- & Oct-40 & No & $\begin{array}{l}\text { Spectroscopy measure } \\
\text { \& quantitative } \\
\text { evaluation with a } \\
\text { software }\end{array}$ & $\begin{array}{l}\text { Hb(total) } \\
\text { Hb oxygen } \\
\text { Hb deoygen }\end{array}$ & $20-30$ \\
\hline $\begin{array}{l}\text { Hb- } \\
\text { P7 }\end{array}$ & 296.4 & $130 \times 72 \times 25$ & No & $0-25$ & May-40 & No & $\begin{array}{l}\text { Spectrophotometry \& } \\
\text { Photoplethysmography } \\
500-1300 \mathrm{~nm}\end{array}$ & $\begin{array}{l}\mathrm{Hb} \text { total } \\
\mathrm{SpO}_{2} \\
\mathrm{PR} \\
\mathrm{PI}\end{array}$ & $30-45$ \\
\hline
\end{tabular}

$\mathrm{Hb}$, hemoglobin; Hb-Hc, Hb hemocue; Hb-NBM, Hb NBM 200; Hb-Ham, Hb haemospect; Hb_P7, Hb pronto 7; PR, pulse rate; SpO , arterial oxygen saturation; $\mathrm{PI}$, perfusion index

The NBM200 system measures $\mathrm{Hb}$ and analyzes the pulse rate by an occlusion spectroscopy system using a throbbing spectroscopy method and a temporary arterial occlusion of 8 wavelengths (red and infrared) to distinguish blood $\mathrm{Hb}$ from other components. The analysis between a wavelength ranges from 600 to $1500 \mathrm{~nm}$ provides the necessary sensitivity for the two measurements. The device consists of a reusable ring-shaped sensor probe that engages the subject's finger, and a portable desktop monitor which calculates and displays the measurement. The monitor has a liquid crystal display (LCD) easy to read that shows the patient's Hb and the pulse rate. The system requires a self-diagnosis at first, weighs $900 \mathrm{~g}$, his dimensions are $7.5 \mathrm{~cm}$ (high), $22.4 \mathrm{~cm}$ (wide) and $18.2 \mathrm{~cm}$ (deep), and can be used by battery or by electrical connection. The screening test is done between 90 to 120 seconds.

The Haemospect method is designed for non-invasive measurement of blood $\mathrm{Hb}$ levels by spectroscopy, with quantitative evaluation using a software (Software used: 01.81.191) and two xenon lamps as light source. Xenon white light is applied to the skin with the help of a sensor. The light penetrates the tissues and a portion of this is reflected in their way through the body, this light portion is transmitted to the optical analysis unit through another optical waveguide integrated in the sensor too. In that unit a spectroscopic analysis is done and evaluated by the software. The device consists of a measurer (digiCLIP) and a portable monitor. The measure is placed on the fingertip of the middle finger and the donor should sit upright, without moving the arm during the measurement. The estimated time of the test is from 20 to 30 seconds. The end of the measurement is indicated by an audible and visual signal on the screen. Haemospects needs an intensity and wavelength calibration to start and it can be used connected to the electricity network or by an autonomous battery. It weights is about $544 \mathrm{~g}$ and his dimensions are $21 \mathrm{~cm} \times 4.2 \mathrm{~cm} \times 11.5 \mathrm{~cm}$.

The Pronto7 TM with rainbow 4TD technology system is designed for rapid, precise and non-invasive measurement of total hemoglobin, arterial oxygen saturation $\left(\mathrm{SpO}_{2}\right)$, heart rate and perfusion index. It uses technology based on pulsio-oximetry, which is governed by two principles (spectrophotometry and Photoplethysmography) and uses a multi-wavelength sensor to distinguish between oxygenated blood, deoxygenated blood and plasma. The sensor signal is obtained by several infrared lights, which range from 500 to $1300 \mathrm{~nm}$, through the capillary bed, measuring absorption changes during blood pulsatile cycle. The sensors receive the light and turn it into an electronic signal that the device receives for its calculation using certain algorithms. Measurement of total $\mathrm{Hb}$ is based in a calibration of the multiwavelength measurement that quantifies the percentage of total blood hemoglobin. Pronto7 can be used with autonomous battery or by electrical connection, it weighs about $0.296 \mathrm{~kg}$, and the dimensions of the device are $13 \mathrm{~cm} \times 7.2 \mathrm{~cm} \times 2.5 \mathrm{~cm}$. The test takes between 30 to 45 seconds. To determine the reproducibility of $\mathrm{Hb}$ measurements with each non-invasive method, 30 measurements were made on consecutive days in 3 staff volunteers with known $\mathrm{Hb}$ with 15.4, 11.8 and $10.3 \mathrm{~g} / \mathrm{dl}$ respectively and the coefficient of variation was calculated.

\section{Statistical analysis}

All data were recorded into a database Excel 2007 version (Microsoft Corporation Redmond WA, USA). Data are shown as mean, standard deviation (SD), maximum value and minimum value. The correlation between the different methods and the error rates referring to the reference method (COULTER LH 750®), the BlandAltman method and the Pearson correlation coefficient were used for analysis. The Bland-Altman measures the strength of relation by a plot of the difference between two methods against the mean value. We considered a good correlation index when Pearson's values were greater than or equal to 0.75 , favorable values between 0.40 to 0.75 and poor values less than 0.40 . Statistical analysis of data was performed using the statistical package SPSS 19 IBM (IBM Corporation 1 New Orchard Road, Armonk, New York 10504-1722 USA) and MedCalc 12.2.1.0 (Ostende, Belgica).

\section{Results}

The characteristics of the study population (age \& gender), heart rate, blood pressure, number of donations and donations in the last year before the study are summarized on Table 2. Results of the $\mathrm{Hb}$ measurements by the different methods and $\mathrm{MCV}, \mathrm{MCH}$ and RDW determinations are summarized on Table 3. Training in the use of non-invasive methods required no more than 45 minutes and did not require any special expertise. The time to measure $\mathrm{Hb}$ was 35 " for HemoCue, 100" for NBM200, 20" for Haemospect and 30" for Pronto7.

There was no influence of heart rate, blood pressure, number of donations and donations in the last year before the study in the results of $\mathrm{Hb}$ measurement with the invasive and non-invasive methods. The usability was evaluated with a questionnaire filled by operators, and the results are summarized in Table 4 . The most satisfactory grade was with HemoCue (mean 4.21), probably because it has been the routine procedure for many years. The other systems were evaluated with a satisfactory level (mean 3.21, 3.89 and 3.93). Pronto 7 was the best rated of the non-invasive devices. 
Table 2 Characteristics of the study population. Heart rate, blood pressure and donations

\begin{tabular}{|c|c|c|c|c|c|c|}
\hline \multirow[b]{2}{*}{ Donors } & \multicolumn{2}{|l|}{ Total(n= I59) } & \multicolumn{2}{|c|}{ Females $(n=57)$} & \multicolumn{2}{|c|}{ Males(n= I02) } \\
\hline & Mean(SD) & Minimum-Maximum & Mean(SD) & Minimum-Maximum & Mean(SD) & $\begin{array}{l}\text { Minimum- } \\
\text { Maximum }\end{array}$ \\
\hline HR & $71.37(11.3)$ & $109-44$ & $74.82(\mid 2.31)$ & $109-52$ & $69.44(10.27)$ & $98-44$ \\
\hline SBP & $128.36(13.64)$ & $103-184$ & $126.44(13.42)$ & $103-155$ & $\mid 29.43(|3.7|)$ & $104-184$ \\
\hline DBP & I5.88(8.30) & $47-95$ & $76.26(7.18)$ & $60-90$ & 75.67(8.89) & $47-95$ \\
\hline MBP & 93.37(9.32) & $68.0-118.3$ & $92.99(8.7 I)$ & $75.67-111.67$ & $93.59(9.54)$ & $68-118.33$ \\
\hline Pulse & $71.37(11.3)$ & $44.0-109.0$ & $74.82(|2.3|)$ & $52-109$ & $69.44(10.27)$ & $44-98$ \\
\hline Total Donations & $9.92(11.14)$ & $0-56$ & $6.6 I(9.5 I)$ & $0-42$ & $11.77(11.60)$ & $0-56$ \\
\hline Donations in the last year & $1.03(0.99)$ & $0-3$ & $0.72(0.88)$ & $0-3$ & $1.20(1.02)$ & $0-3$ \\
\hline
\end{tabular}

$\mathrm{HR}$, heart rate; SBP, systolic blood pressure; DBP, diastolic blood pressure; MBP, mean blood pressure

Table $3 \mathrm{Hb}$ levels using Hb-V(reference value), Hb-Hc, Hb-NBM, Hb-Ham, Hb-P7, and characteristics of the study population

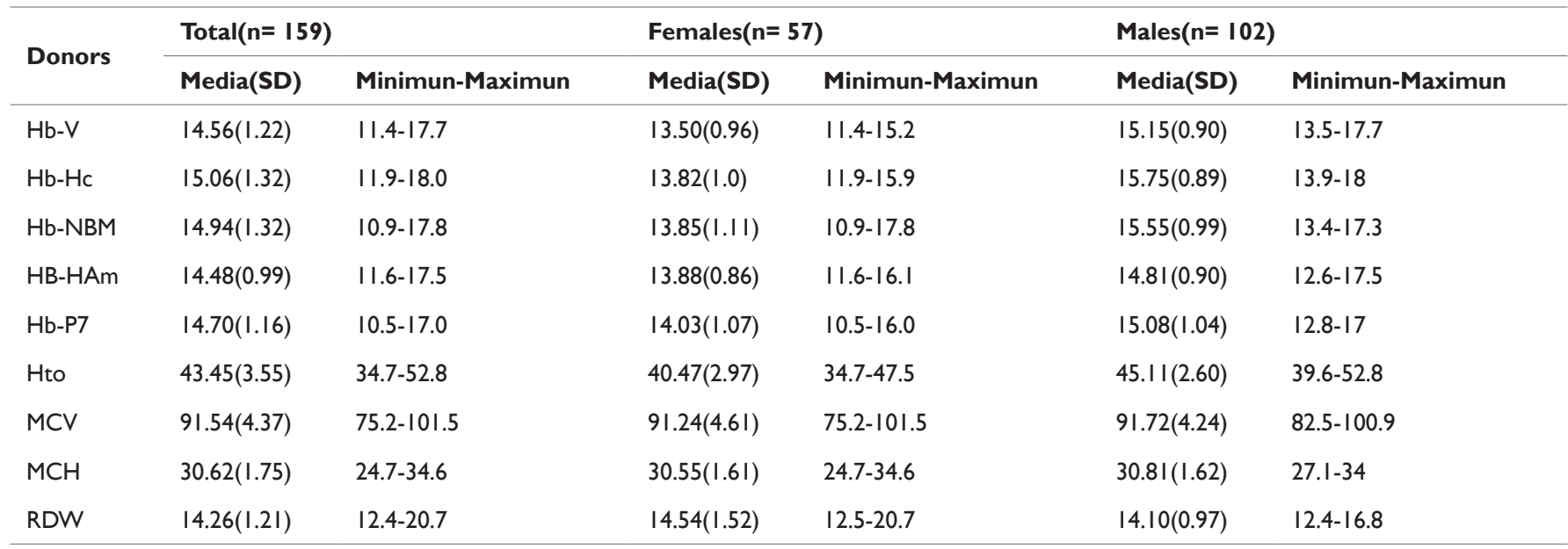

Hb, hemoglobin; Hb-Hc, Hb hemocue; Hb-NBM, Hb NBM 200; Hb-Ham, Hb haemospect; Hb P7, Hb pronto 7; Hto, hematocrito; MCV, mean corpuscular volume; $\mathrm{MCH}$, mean corpuscular hemoglobin; RDW, red distribution wide

Table 4 Assessment of usability

\begin{tabular}{lllll}
\hline & HemoCue & Haemospect & NBM200 & PRONTO 7 \\
\hline Easy to Use & 4.25 & 4 & 4.25 & 4.5 \\
Time to Measure & 4.5 & 4.25 & 1.75 & 4.25 \\
Cleaning & 3.75 & 3.75 & 3.25 & 3.75 \\
Maintenance & 4 & 3.75 & 4 & 4 \\
Intrinsic Errors & 4 & 3 & 3 & 3 \\
Light Ambient Sensibility & 4.5 & 4.25 & 2.75 & 3 \\
Handling & 4.5 & 4.25 & 3.5 & 5 \\
Global Mean & 4.21 & 3.89 & 3.21 & 3.93 \\
\hline
\end{tabular}

Scale evaluated from 0 (unsatisfactory) to 5 (excellent)

Figures 1-4 show Bland Altman plots and linear regression analysis for the different screening methods and venous $\mathrm{Hb}$ measurement with Coulter LH750. Bland Altmant plots represent the bias (solid line) and the $95 \%$ limit of agreement (LOA) between the test method and the gold standard method (CBC). The best correlation was obtained with HemoCue, results with NBM 200 and Pronto 7 were similar, and the worst result, although acceptable, was with Haemospect.
The correlation index (Pearson) with venous $\mathrm{Hb}$ as reference was 0.859 for HemoCue, 0.648 for NBM 200, 0.618 for Pronto 7 and 0.416 for Haemospect. The $95 \%$ limits of agreement were 14.37-14.74 for CBC, 14.85-15.26 for HemoCue, 14.32-14.63 for Haemospect, 14.5014.89 for Pronto7 and 14.74-15.15 for NBM200. HemoCue showed a good Pearson index and the non-invasive devices showed favorable correlations having the Haemospect device the worst index. 


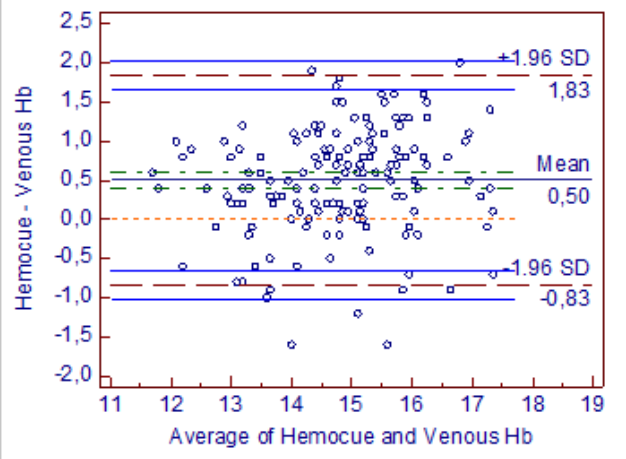

(A)

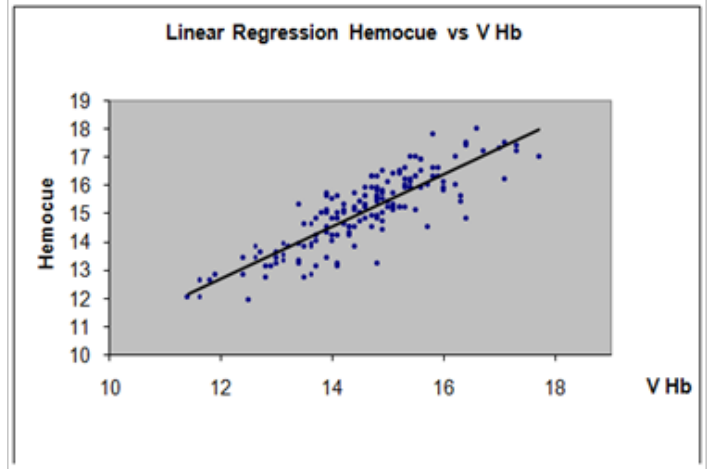

(B)

Figure I (A) Bland Altman plot show a bias of $0.5 \mathrm{~g} / \mathrm{dl}$, SD I.96 and LOA from -0.83 to I.83 (B) Bland Altman plot and Linear regression of Hemocue $30 \mathrm{I}$ \& LH $750(\mathrm{~V} \mathrm{Hb})$

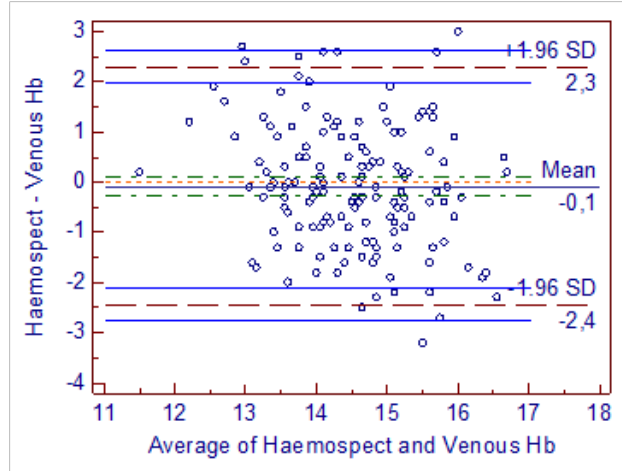

(A)

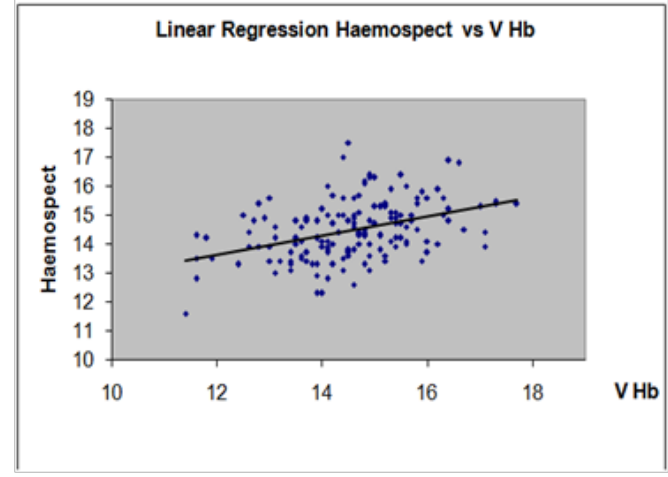

(B)

Figure 2 (A) Bland Altman plot show a bias of 0.1 g/dl, SD 1.96 and LOA from -2.4 to 2.3 (B) Bland Altman plot and linear regression of Haemospect \& LH $750(\mathrm{~V} \mathrm{Hb})$.

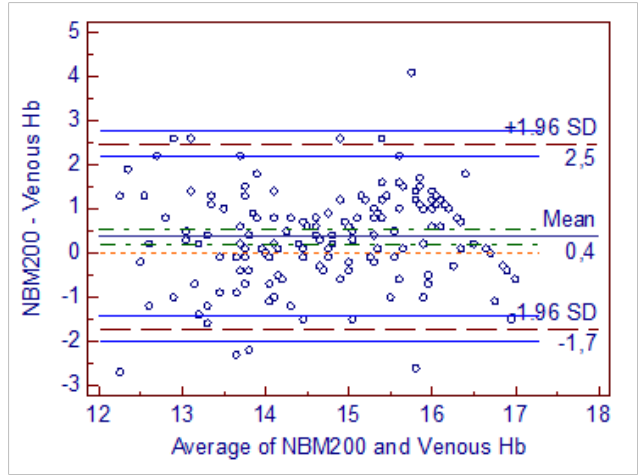

(A)

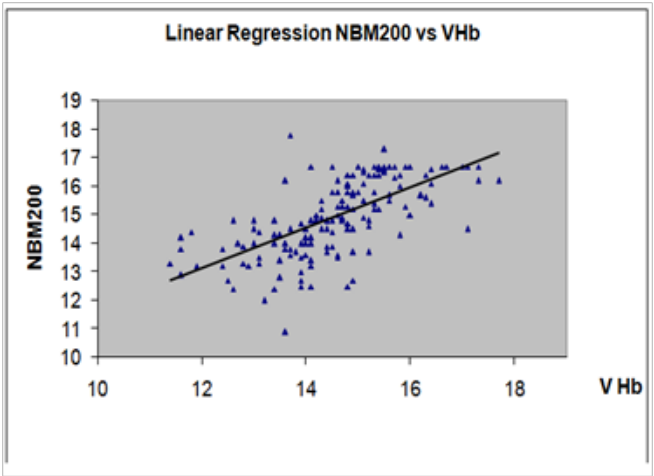

(B)

Figure 3 (A) Bland Altman plot show a bias of $0.4 \mathrm{~g} / \mathrm{dl}$, SD I.96 and LOA from - I.7 to 2.5 (B) Bland Altman plot and linear regression of NBM 200 \& LH 750 ( $\mathrm{VHb})$.

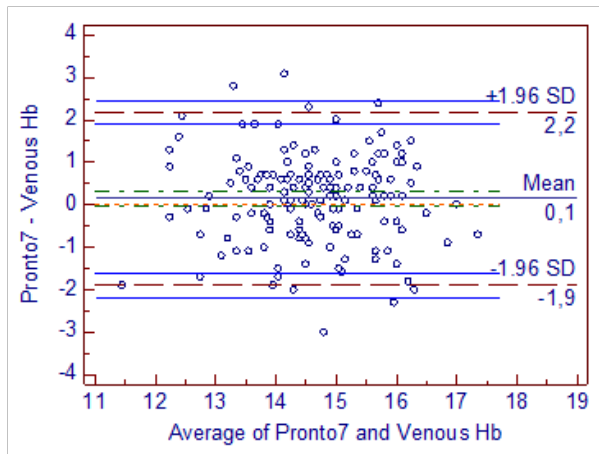

(A)

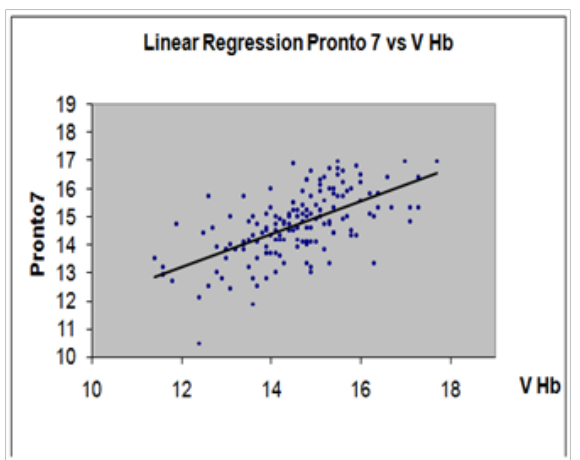

(B)

Figure 4 (A) Bland Altman plot show a bias of 0.Ig/dl, SD 1.96 and LOA from - 1.9 to 2.2 (B) Bland Altman plot and Linear regression of Pronto7 \& LH 750 ( $\mathrm{Hb})$.

Citation: Pajares-Herraiz AL, Rodriguez-Gambarte JD, Eguia-Lopez B, et al.A comparative study of three non-invasive systems for measurement of hemoglobin with hemocue system having coulter LH750 as reference value. Hematol Transfus Int J. 20I5; I (3):68-74. DOI: 10.15406/htij.20I5.0I.000I6 
Using the $\mathrm{Hb}$ with $\mathrm{CBC}$ as reference standard, the percentage of donors correctly screened for blood donation by HemoCue was $95.6 \%, 91.8 \%$ by NBM200 \& Haemospect and $89.9 \%$ by Pronto 7 (Table 5). Regarding sex, we found worst percentages in women than in men, especially with NBM 200 and Haemospect. The sensitivity, reflected as percentage of donors unacceptable with $\mathrm{CBC}$ that were unacceptable by the method, was $96.23 \%$ for HemoCue, $91.19 \%$ for Pronto 7, 93.08\% for Haemospect, and $94.34 \%$ for NDM200. The specificity, i.e. percentage of donors acceptable with CBC that were acceptable with the method, was $99.37 \%$ for HemoCue, $98.74 \%$ for Pronto7 and Haemospect, and 97.48\% for NBM200. The HemoCue method showed better sensitivity and specificity. Among the noninvasive devices, NBM200 had better sensitivity and Pronto 7 and Haemospect had better specificity. Thus, the ability of non-invasive methods to determine an acceptable donor is greater than their ability to determine an unacceptable one. The three non-invasive methods for hemoglobin determination used in the study displayed acceptable reproductibility.

Table 5 Donors accepted or rejected with invasive and non-invasive methods according to the CBC value*

\begin{tabular}{|c|c|c|c|c|c|c|c|c|c|}
\hline & \multicolumn{3}{|c|}{ Rejected Falsely(n/\%) } & \multicolumn{3}{|c|}{ Accepted Falsely(n/\%) } & \multicolumn{3}{|c|}{ Accepted Correctly(n/\%) } \\
\hline & $M(152)$ & $\mathbf{F ( 5 7 )}$ & Total(I59) & $M(152)$ & $\mathbf{F}(57)$ & Total(I 59) & $M(152)$ & $\mathbf{F ( 5 7 )}$ & Total(I 59) \\
\hline HemoCue & $0 / 0$ & $6 / 10.5$ & $6 / 3.77$ & $0 / 0$ & I / I.75 & $1 / 0.63$ & $102 / 100$ & $50 / 87.72$ & $152 / 95.6$ \\
\hline PRONTO 7 & $8 / 7.8$ & $6 / 10.5$ & 14 / $8.8 \mid$ & $0 / 0$ & $2 / 3.51$ & $2 / 1.26$ & $94 / 92.16$ & 49 / 85.96 & $143 / 89.93$ \\
\hline Haemospect & $4 / 3.92$ & $7 / 12.3$ & $11 / 6.92$ & $0 / 0$ & $2 / 3.51$ & $2 / 1.26$ & $98 / 96.08$ & 48 / 84.21 & $146 / 91.82$ \\
\hline NBM 200 & I / 0.98 & I4-Aug & $9 / 5.66$ & $0 / 0$ & $4 / 7.02$ & $4 / 2.52$ & $101 / 99.02$ & $45 / 78.95$ & |46 / 91.82 \\
\hline
\end{tabular}

*Data are reported as number/\%; $M$, male; F, female; $n$, number

\section{Discussion}

To avoid anaemia in blood donors and to ensure a good Hemoglobin content in the blood components, Hb screening is an essential part of blood donation. In our study, we attempted to assess the accuracy of some non-invasive $\mathrm{Hb}$ screening methods compared to the HemoCue 301 system, and $\mathrm{Hb}$ measure with $\mathrm{CBC}$ as a gold standard. $\mathrm{Hb}$ levels are mostly obtained in our media with capillary systems as the HemoCue method. This system has been validated and used widely around the world ${ }^{13,14,26,27}$ but the use of a fingerstick has been reported as one of the worst parts of blood donation. ${ }^{28}$ This makes it necessary to investigate and to develop a non-invasive method of $\mathrm{Hb}$ screening and make the blood donation a good and comfortable experience. Some non-invasive $\mathrm{Hb}$ screening devices have been used and validated during the last years in many medical areas. ${ }^{18-21,24}$ Moreover, these methods are being used at blood transfusion centers compared to other invasive systems around the world to improve donor satisfaction and increase the willingness to donate in the future. ${ }^{29}$

The ideal HB screening method should be easy handling, noninvasive, inexpensive, with a good sensitivity and specificity index, and should provide accurate results to avoid anaemia in blood donors. The venous sample for $\mathrm{Hb}$ screening is the gold standard but is not logistically admitted in blood donor selection, however the validation of any method, invasive or non-invasive, should be done in comparison to $\mathrm{CBC} \mathrm{Hb}$ screening.

Although other studies have compared different systems, ${ }^{23,30-32}$ our study investigates the accuracy of three non-invasive methods comparing with the invasive HemoCue and having the CBC Coulter LH 750 as gold standard reference. We found that any of these non-invasive portable systems is clearly superior to any other and that the HemoCue method is superior to non-invasive systems. The Haemospect method was faster than other non-invasives devices and HemoCue. Usability was better with Pronto7 device comparing with other non-invasive methods. The correlation index, Bland Altmant plot and linear regression showed that the Haemospect had low correlation index comparing with other systems, but with acceptable values. The ability of non-invasive methods to determine an acceptable donor is greater that their ability to determine an unacceptable one. The problem seems to be in the pre-analytical variability of sampling, the ambient temperature, the colour of skin, anatomic differences in the venous circulation and capillary of the finger. These considerations could explain the results in women. Venous hemoglobin levels are consistently and predictibly higher than the capillary $\mathrm{Hb}$ level in the same donor ${ }^{27}$ and we must have this point in consideration when using non-invasive methods too.

\section{Conclusion}

Our study demonstrate that HemoCue method is better correlationated with venous $\mathrm{Hb}$, but the NBM200, Haemospect and Pronto 7 could be used as screening test for blood donation as we used the HemoCue system at this moment, although we must have in consideration that their ability to determine an acceptable donor is greater that their ability to determine an unacceptable one. These three methods will be better when better software and algorithms are developed, making $\mathrm{Hb}$ screening in blood donors more comfortable and painless. Non-invasive systems are safer in relation to job security than other systems involving puncture.

\section{Acknowledgements}

We thank our blood donation and apheresis staff for their job day after day as well as our blood donors from Toledo County in Spain for their solidarity and altruism.

\section{Conflict of interest}

The author declares no conflict of interest.

\section{References}

1. Council of Europe. Guide to the Preparation, Use and Quality Assurance of Blood Components. 18th ed. Strasbourg, France; 2015.

2. Real Decreto $1088 / 2005$ de 16 de Septiembre por el que se establecen los requisitos técnicos y condiciones mínimas de la hemodonación y de los centros y servicios de transfusión. Ministerio de Sanidad y Consumo España, BOE 225; 2005

3. Agência Nacional de Vigilância Sanitária (Anvisa). Resolução RDC n⿳亠 57, de 17 de outubro de 2010. Diário Oficial da União, Brasil: Ministério da Saude; 2010. 
4. Stern M, O’Meara A, Infanti L, et al. Prognostic value of red blood cell parameters and ferritin in predicting deferral due to low hemoglobin in whole blood donors. Ann Hematol. 2012;91(5):775-780.

5. United States code of federal regulations, Title 21, 640 .

6. Price TH. Standards for blood and transfusion services. 25th ed Bethesda, USA: American Association of Blood Banks; 2008. 45 p.

7. Cable RG, Steele WR, Melmed RS, et al. The difference between fingerstick and venous hemoglobin and hematocrit varies by sex and iron stores. Transfusion. 2012;52(5):1031-1040.

8. Gonçalez TT, Sabino EC, Schlumpf KS, et al. Analysis of donor deferral at three blood centers in Brazil. Transfusion. 2013;53(3):531-538.

9. Hillgrove T, Moore V, Doherty K, et al. The impact of temporary deferral due to low hemoglobin: future return, time to return, and frequency of subsequent donation. Transfusion. 2011;51:539-547.

10. Mast AE, Schlumpf KS, Wright DJ, et al. Wright Demographic correlates of low hemoglobin deferral among prospective whole blood donors. Transfusion. 2010;50:1794-1802.

11. James V, Jones KF, Turner EM, et al. Statistical analysis of inappropiate results from current hemoglobin screening methods for blood donors. Transfusion. 2003;43(3):400-404.

12. Cable RG. Hemoglobin determination in blood donors. Transfus Med Rev. 1995;9(2):131-144.

13. Sanchis-Gomar F, Cortell-Ballester J, Pareja-Galeano $\mathrm{H}$, et al. Hemoglobin point-of-care testing: the hemocue system. J Lab Autom 2013;18(3):198-205.

14. Morris LD, Osei-Bimpong A, McKeown D, et al. Evaluation of the utility of the HemoCue 301 haemoglobinometer for blood donor screening. Vox Sang. 2007;93(1):64-69.

15. Bahadur S, Jain S, Jain M. Estimation of hemoglobin in blood donors: A comparative study using hemocue and cell counter. Transfus Apher Sci. 2010;43(2):155-157.

16. Gómez-Simón A, Navarro-Núñez L, Pérez-Ceballos E, et al. Evaluation of four rapid methods for hemoglobin screening of whole blood donors in mobile collection settings. Transfus Apher Sci. 2007;36(3):235-242.

17. Patel AJ, Wesley R, Leitman SF, et al. Capillary versus venous haemoglobin determination in the assessment of healthy blood donors Vox Sang. 2013;104(4):317-323.

18. Miller RD, Ward TA, Shiboski SC, et al. A comparison of three methods of hemoglobin monitoring in patients undergoing spine surgery. Anesth Analg. 2011;112(4):858-863.

19. Shamir MY, Avramovich A, Smaka T. The current status of continuous noninvasive measurement of total, carboxy, and methemoglobin concentration. Anesth Analg. 2012;114(5):972-978.
20. Lamhaut L, Apriotesei R, Combes X, et al. Comparison of the accuracy of noninvasive hemoglobin monitoring by spectrophotometry $(\mathrm{SpHb})$

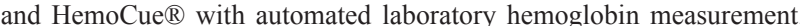
Anesthesiology. 2011;115(3):548-554.

21. Gayat E, Aulagnier J, Matthieu E, et al. Non-invasive measurement of hemoglobin : assessment of two different point-of-care technologies. Plos One. 2012;7(1):e30065.

22. Pinto M, Barjas-Castro ML, Nascimento S, et al. The new noninvasive occlusion spectroscopy hemoglobin measurement method: a reliable and easy anemia screening test for blood donors. Transfusion. 2013;53(4):766-769.

23. Belardinelli A, Benni M, Tazzari PL, et al. Noninvasive methods for haemoglobin screening in prospective blood donors. Vox Sang. 2013;105(2):116-120.

24. Crowley C, Montenegro-Bethancourt G, Solomons NW, et al. Validity and correspondence of non-invasively determined hemoglobin concentrations by two trans-cutaneous digital measuring devices. Asia Pac J Clin Nutr. 2012;21(2):191-200.

25. Rabe H, Stupp N, Ozgün M, et al. Measurement of transcutaneous hemoglobin concentration by non-invasive white light spectroscopy in infants. Pediatrics. 2005;116(4):841-843.

26. Mendrone A, Sabino EC, Sampaio L, et al. Anemia screening in potential female blood donors: comparison of two different quantitative methods. Transfusion. 2009;49(4):662-668.

27. Tong E, Murphy WG, Kinsella A, et al. Capillary and venous haemoglobin levels in blood donors: a 42-month study of 36258 paired samples. Vox Sang. 2010;98(4):547-553.

28. Oswalt RM. A review of blood donor motivation and recruitment Transfusion. 1977;17(2):123-135.

29. Kim MJ, Park Q, Kim MH, et al. Comparison of the accuracy of noninvasive hemoglobin sensor (NBM 200) and portable hemoglobinometer (hemocue) with an automated hematology analyzer (LH500) in blood donor screening. Ann Lab Med. 2013;33(4):261-267.

30. Ardin S, Störmer M, Radojska S, et al. Comparison of three methods for hemoglobin screening of blood donors. Transfusion. 2015;55(2):379387.

31. Pajares Al, Rollon N, Barea LM. Evaluacion comparativa del método invasivo Hemocue con el no invasivo Pronto7 para la medición de Hemoglobina predonación. Blood Transfusion. 2013;(Suppl 3):s118.

32. Pérez S, Alonso V, Salas H. Evaluación de la medición de Hemoglobina por el método no invasivo Pronto 7. Blood Transfusion. 2012;10(Suppl 3):s129. 